\title{
The effects of ejector adiabatic absorber on heat and mass transfer of binary nanofluid with heat transfer additives
}

\author{
Umar Aliyu Muhammad ${ }^{1}\left[\right.$ [ Debabratta Bhattacharyya ${ }^{1} \cdot$ Jose Louis Endrino $^{2} \cdot$ Sonia Fereres $^{3}$
}

Received: 29 April 2021 / Accepted: 9 August 2021 / Published online: 30 August 2021

(c) The Author(s) 2021

\begin{abstract}
This paper presents experimental results on the study of the effects of ejector adiabatic absorber on heat and mass transfer of binary nanofluid with heat transfer additives (2-ethyl-1-hexanol and gum Arabic). In this case, $\mathrm{H}_{2} \mathrm{O} /$ lithium bromide-alumina nanofluid was suggested due to a growing interest in absorption heat transfer working fluid for solar energy application. An experimental setup - ejector test rig - was designed to study the absorption, heat, and mass transfer rate as a result of refrigerant vapour mass flow entrained by the ejector adiabatic absorber. The study was carried out at different solution mass flowrate ( 0.051 to $0.17 \mathrm{~kg} / \mathrm{s}$ ) with three prepared sample solutions, which include pure $\mathrm{LiBr}$ solution, LiBr-Alumina nanofluid without heat transfer additives, and LiBr-Alumina nanofluid with heat transfer additives. The absorption rate, mass transfer coefficient, heat transfer rate, and heat transfer coefficient for the three samples were reported. On the other hand, the percentage enhancements for all the parameters — at a suitable flow rate of $0.085 \mathrm{~kg} / \mathrm{s}$ - due to the addition of alumina without and with heat transfer additives were recorded. The absorption rate enhancements were $25 \%$ and $96 \%$, the enhancement rates of mass transfer coefficient recorded were $20 \%$ and $82 \%$, the heat transfer rate enhancements were $85 \%$ and $183 \%$, and the heat transfer coefficient enhancements obtained were $72 \%$ and $156 \%$ with addition of alumina nanoparticles only and alumina nanoparticles with heat transfer additives respectively. Material mass balance analysis suggests that mass inflow in the ejector equals to the mass outflow from the ejector, indicating a complete absorption of the entrained refrigerant vapour beyond which falling film absorption can occur due to concentration. This article also presents experimental evidence of the capability of ejector as strong adiabatic absorber, heat, and mass transfer component, which were earlier reported using numerical models.
\end{abstract}

Keywords Absorption refrigeration · Thermofluids · Working fluid $\cdot$ Heat recovery $\cdot \mathrm{H} 2 \mathrm{O} / \mathrm{LiBr}$

\begin{tabular}{ll}
\multicolumn{2}{l}{ Nomenclature } \\
2E1H & 2-Ethyl-1-hexanol \\
A & Area, m ${ }^{2}$ \\
AG & Arabic gum
\end{tabular}

Umar Aliyu Muhammad

drmaumar1@gmail.com

Debabratta Bhattacharyya

dbhat146@gmail.com

Jose Louis Endrino

jose.endrino@nano4energy.eu

Sonia Fereres

sonia.fereres@abengoa.com

1 School of Aerospace, Transport and Manufacturing, Cranfield University, Cranfield MK43 0AL, Bedfordshire, UK

2 Nano4Energy SLNE, Madrid, Spain

3 Abengoa Energy Company, Seville, Spain

$\begin{array}{ll}\text { ANF } & \text { Alumina nanofluid } \\ \text { ANPs } & \text { Alumina nanoparticles } \\ \mathrm{COP}_{\mathrm{T}} & \text { Thermal coefficient of performance } \\ C p & \text { Specific heat capacity, } \mathrm{kJ} / \mathrm{kgK} \\ \mathrm{EB} & \text { Ejector booster } \\ h & \text { Heat transfer coefficient, } \mathrm{kW} / \mathrm{m}^{2} \mathrm{~K} \\ H & \text { Enthalpy, } \mathrm{kJ} / \mathrm{kg} \\ \mathrm{HTA} & \text { Heat transfer additives } \\ \mathrm{HTR} & \text { Heat transfer rate } \\ \mathrm{HTC} & \text { Heat transfer coefficient } \\ k & \text { Thermal conductivity, } \mathrm{mW} / \mathrm{m} . \mathrm{K} \\ \dot{\mathrm{m}} & \text { Mass flowrate, } \mathrm{kg} / \mathrm{s} \\ \mathrm{MTC} & \text { Mass transfer coefficient } \\ \Delta \dot{\mathrm{m}}_{\mathrm{ar}} & \text { Absorption rate, } \mathrm{kg} / \mathrm{s} \\ \Delta T & \text { Change in temperature } \\ Q & \text { Heat transfer rate, } \mathrm{W} \\ T & \text { Temperature, } \mathrm{K} \\ U & \text { Global heat transfer coefficient, } \mathrm{W} / \mathrm{m}^{2} \mathrm{~K} \\ x & \text { LiBr mass fraction }\end{array}$

ANF Alumina nanofluid

ANPs Alumina nanoparticles

$\mathrm{COP}_{\mathrm{T}} \quad$ Thermal coefficient of performance

$C p \quad$ Specific heat capacity, $\mathrm{kJ} / \mathrm{kgK}$

EB Ejector booster

H

HTA

HTR

HTC

$k$

$\dot{\mathrm{m}}$

MTC

LiBr mass fraction

,




\section{Greek}

$\beta \quad$ Mass transfer coefficient, $\mathrm{m} / \mathrm{s}$

$\rho \quad$ Density, $\mathrm{kg} / \mathrm{m}^{3}$

\section{Subscripts}

$\begin{array}{ll}\text { ar } & \text { Absorption rate } \\ b f & \text { Base fluid } \\ c & \text { Coolant } \\ d & \text { Discharge } \\ \text { in } & \text { Inlet } \\ n f & \text { Nanofluid } \\ \text { out } & \text { Outlet } \\ p & \text { Primary } \\ \text { sol } & \text { Solution }\end{array}$

\section{Superscripts}

$e q \quad$ Equilibrium

\section{Introduction}

Ecological devices, which control temperature, are essential and important for the environment and our own society [1-6]. They are currently an integral part of the large number of industries for further growth and low-carbon processes [7]. The area of this niche application is very wide, and it ranges from energy management of buildings [8], electronic devices [9], and food preservation [10], to industrial and residential heating and cooling [11]. Refrigeration systems play a vital role in improving the entire living conditions of human life [12], and hence, the method of absorption cycle of refrigeration and their improvement have gained immense interest. As stated by Bravo et al. [13], it enhances the efficiency of utilisation of low-grade heat. The frequent use of such particular fluids with absorption cycles are the solutions of $\mathrm{LiBr}$ and $\mathrm{NH}_{3} . \mathrm{H}_{2} \mathrm{O} / \mathrm{LiBr}$ pair is used in air conditioning of room or space cooling. $\mathrm{NH}_{3} / \mathrm{H}_{2} \mathrm{O}$ brings into effective action for the cooling factor of the sub-zero degree Celsius element and air infiltration of freeness. $\mathrm{H}_{2} \mathrm{O} / \mathrm{LiBr}$ systems are associated with crystallisation and corrosion issues, which need further research. However, the $\mathrm{NH}_{3} / \mathrm{H}_{2} \mathrm{O}$ system requires a very costly rectifier, which separates two ionic liquids, since, in the generator, both water vapour and ammonia are produced [14]. This is expected to overcome many of the promising properties of the refrigerant because of its large latent heat, low costs, and very low impact on the environment.

Absorption refrigeration systems have emerged as a means of substituting the conventional vapour compression refrigeration systems, as they can utilise various forms of renewable energy sources such as solar energy and waste heat from industrial processes to enhance a friendly environment $[15,16]$. The absorption process in refrigeration generally involves the use of a basic solution here called the absorbent to take in the refrigerant vapour which itself becomes weaker until the refrigerant is evaporated in the generator [16]. The process of generating high-pressure refrigerant vapour from weak/dilute solution in the generator to the condenser and the reabsorption of the low-pressure refrigerant vapour by the absorbent (strong solution) from the evaporator back to the generator is known as the refrigeration cycle. Air conditioning uses vapour absorption refrigeration system with the use of water-lithium bromide pair. This system does not provide the sub-zero degrees temperature for refrigeration. As refrigeration do not go beyond $273 \mathrm{~K}$, therefore, it is used in the applications, which requires the temperature above $273 \mathrm{~K}$, thus allowing room temperature operation.

The selection of working fluid pair, particularly the refrigerant, is pivotal as it regulates the working conditions of the absorption refrigeration system [16]. The properties of good refrigerants include having low molecular mass, high enthalpy of vaporisation and cooling capacity, and also being non-flammable and nontoxic, which are exhibited by the natural refrigerant, water [17]. $\mathrm{H}_{2} \mathrm{O} / \mathrm{LiBr}$ pair is one of the most widely used and effective working fluid pairs in absorption refrigeration systems due to their environmental friendly and nontoxic nature $[18,19]$. This working fluid pair is widely utilised in large air conditioning and food preservation systems in which $\mathrm{LiBr}$ solution serves as the absorbent and water as the refrigerant [20]. The absorption properties and heat and mass transfer rates of this working fluid $\left(\mathrm{H}_{2} \mathrm{O} / \mathrm{LiBr}\right)$ can be enhanced by the addition of fine particles [21], and additives — such as gum Arabic (a dispersion stabilisation agent) and 2-ethyl1-hexanol (a surfactant) - according to Lee et al. [22]. The surfactant, 2-ethyl hexanol, is a very important additive in $\mathrm{H}_{2} \mathrm{O} / \mathrm{LiBr}$ working fluid as it reduces surface tension [23, $24]$ and decreases crystallisation temperature [25, 26] of the solution.

Recently, research has gained momentum in ejectors for use in absorption refrigeration systems as adiabatic absorbers. Ejectors or jet pumps utilise pressure energy contained in high-pressure fluids to entrain low-pressure fluids in a system, thus increasing system and cycle efficiency [27]. In addition, in absorption refrigeration system, ejectors are used for entrainment of refrigerants and/or recovery of waste heat and mixing them with the high-pressure strong base solution. Hence, this acts as a very compact adiabatic absorber [27, 28]. Since the ejector has no movable parts, no fuel or lubrication is required; therefore, no maintenance cost is involved. In addition, the device is also known for pressure increase without direct mechanical energy consumption, which is the main characteristic. This allows the ejector to be compact and cheaper than installing other devices to generate pressure, such as multiple pumps and compressors $[29,30]$. 
Vereda et al. [27] in their numerical model had shown that absorption refrigeration system incorporated with an ejector has even higher thermal coefficient of performance at lower driving temperature compared to both systems with diabatic absorber and conventional adiabatic absorber at a higher driving temperature. A simulation model presented by Manu et al. [31] on single-stage vapour absorption of $\mathrm{H}_{2} \mathrm{O} / \mathrm{LiBr}$ in a heat pump for cooling electronic chips had proposed a superior absorber load reduction. It also shows an improvement in coefficient of performance (COP) by over $17 \%$ ( 0.7145 to 0.8421$)$ as chip temperature rises from 303 to $323 \mathrm{~K}$. The model was also compared and confirmed numerically to those of Rubio-Maya et al. [32], Ebrahimi et al. [33], and Joudi and Lafta [34] with minor deviations. However, these theoretical studies were not experimentally verified. In another work by Hasan Sh. Majdi [35], a computer simulation program was developed to modify a solar-assisted absorption refrigeration cycle with $\mathrm{H}_{2} \mathrm{O} / \mathrm{LiBr}$ through the introduction of an ejector. The findings had revealed a remarkable improvement of 30-85\% enhancement of the coefficient of performance (COP) at evaporator temperature between 273 and $283 \mathrm{~K}$, and 8-60\% between 298 and $318 \mathrm{~K}$ temperatures of the condenser for same operating conditions obtained by a basic cycle. This is yet another rumination of the capabilities of the component working with $\mathrm{H}_{2} \mathrm{O} / \mathrm{LiBr}$.

Several experimental investigations have been carried out recently on thermal performance of heat transfer system using nanofluid as the working fluid. Arya et al. [36] studied thermal performance of a flat heat pipe using carbon nanotube-water nanofluid, and the results obtained were fascinating. An optimum value of 0.8 filling ratio and $40 \%$ enhancement of heat transfer coefficient (HTC) were obtained from an experimental test rig. Another experimental investigation vindicates that pool boiling heat transfer coefficient increases with increase in heat flux, while the presence of surfactants in nanofluid reduces surface tension of the fluid, which results to significant bubble formation and transport, and this enhances heat transfer from heating source [37]. Sarafraz et al. [37] reported enhancement in heat transfer with significant surface wettability due to addition of a small amount (0.1 wt.\%) of surfactants; SDS, SDBS, and Triton $\mathrm{X}-100$ in $\mathrm{CuO}$-water nanofluid. Heat transfer is found to shrink due to fluid backflows when velocity is increased; however, its mechanism is changed. On the other hand, fluid velocity decrease leads to the attainment of maximum friction coefficient and increase velocity gradient effects and velocity boundary layer augmentation. The behaviour of heat transfer of nanofluids in a cavity shows that augmenting both Reynolds number and nanoparticle concentration results to an increase in heat absorption and uniform temperature distribution [38]. Li et al. [39] also reported the presence of nanoplatelets of graphene enhances thermal conductivity from 0.61 to $0.67 \mathrm{~W} /(\mathrm{mK})$ and heat transfer mechanism as a result of thermophoresis effects and heat transfer boosting. Furthermore, a considerable increase in HTC was reported by augmenting nanofluid flowrate and heat flux [40]. In addition, nanoparticle concentration was said to improve HTC in force convective heat transfer region, but diminishes HTC in the nucleate boiling region [40]. For both force convective and nucleate boiling heat transfer regions, HTC is strongly controlled by heat and mass flux. These recent experimental investigations on thermal performance of heat transfer systems have identified the remarkable influence of nanoparticles and surfactants for improved performance.

Most of the literatures reviewed presented numerical models on the efficiency of ejector adiabatic absorber but not verified experimentally in real-time applications. Although the ejector adiabatic absorber technology is already known for absorption refrigeration, the lack of sufficient validation experimentally has retarded rapid implementation of this new innovative technology by industries and manufacturers of heat pumps and refrigeration systems. In this work, an experimental approach was undertaken to explore the extensive theoretical models proving the potential for the technology. $\mathrm{H}_{2} \mathrm{O} / \mathrm{LiBr}$-Alumina nanofluid is chosen due to its high demand and its recent development in absorption heat transfer fluid for solar energy applications. Incorporating the working fluid pair with heat transfer additives such as 2-ethyl-1-hexanol (2E1H) and gum Arabic (GA) could improve its absorption, heat, and mass transfer rates according to Lee et al. [22]. This is the first experimental study of a custom-made ejector adiabatic absorber with similar working fluid. Lee et al. [22] studied the effect of the heat transfer additives on the falling film absorption of $\mathrm{H}_{2} \mathrm{O} / \mathrm{LiBr}-$ Alumina nanofluid, which is the only similar study closely related to the present article. This article will present an ejector experimental test rig for testing the novel working fluid. An ejector designed and fabricated with minimum pressure loss is proposed to be suitable. This integrated setup of $\mathrm{H}_{2} \mathrm{O} / \mathrm{LiBr}$-Alumina nanofluid with ejector adiabatic absorber is intended for possible application in solar energy system with the scope of further reduction in maintenance cost, complexity of solar trigeneration system, and system efficiency improvement.

\section{Methodology}

\subsection{Materials}

This section focusses on the preparation of nanofluid incorporating $0.01 \mathrm{wt} \%$ of alumina nanoparticles (ANPs) in an aqueous solution of $55 \%$ by weight $\mathrm{LiBr}$ basefluid. In addition, $150 \mathrm{ppm}$ of surfactant $(2 \mathrm{E} 1 \mathrm{H})$ and $0.01 \mathrm{wt} \%$ of gum Arabic (GA) - a dispersion stabilising agent — were added

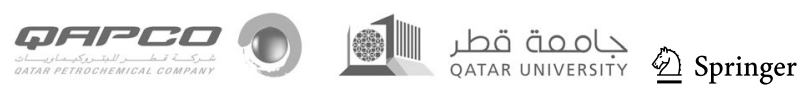


into the basefluid for mass and heat transfer enhancement of the nanofluid. The nanofluid was prepared into three various sample compositions. These samples were used in an ejector-boosted absorption system for evaluation of absorption, heat, and mass transfer performance. The reagents used for the chemical synthesis of the LiBr-ANF include aqueous $\mathrm{LiBr}$ solution (55\%wt), $\mathrm{Al}_{2} \mathrm{O}_{3}$ nanoparticles $(20 \mathrm{~nm})$, gum Arabic powder, and $2 \mathrm{E} 1 \mathrm{H}$, which are all of high purity, purchased from Sigma-Aldrich (Table 1).

\subsection{Sample preparation}

Three samples were prepared for examination with a prototype ejector-boosted absorption system. The samples include sample 1, LiBr solution (55\% wt.); sample 2, LiBr-ANF without HTA; and sample 3, LiBr-ANF with HTA. Sample 1 was prepared from anhydrous $\mathrm{LiBr}$ and distilled water. Samples 2 and 3 were prepared using the two-step method for nanofluid synthesis. The two-step method involves the dispersion of the ANPs into the base fluid, $\mathrm{LiBr}$ solution, followed by magnetic stirring for $30 \mathrm{~min}$ and then ultrasonication for $150 \mathrm{~min}$ to obtain the corresponding nanofluid. However, in preparing sample 3, ANPs were initially treated with the surfactant, $2 \mathrm{E} 1 \mathrm{H}$ for surface functionalization, while the base fluid, $\mathrm{LiBr}$ solution, was prepared with gum Arabic (GA) powder added. The surface functionalized ANPs were allowed to stand for 20 min for proper adsorption before dispersion. This method of nanofluid preparation with HTA was designed and reported by Muhammad et al. [41] (Fig. 1).

\subsection{Experimental rig setup}

An experimental test rig was set up to conduct the series of measurements using a custom-made ejector adiabatic absorber by Transvac Systems Limited, UK. The ejector was designed based on the parameters required for these particular measurements, and the specifications were provided to the supplier for fabrication of the dedicated ejector unit. Emphasis was given to the study of absorption refrigeration phenomena in a closed-loop circulation having intended application in a trigeneration system. The working fluid, $\mathrm{H}_{2} \mathrm{O} / \mathrm{LiBr}-\mathrm{ANF}$, was circulated by pumping into the
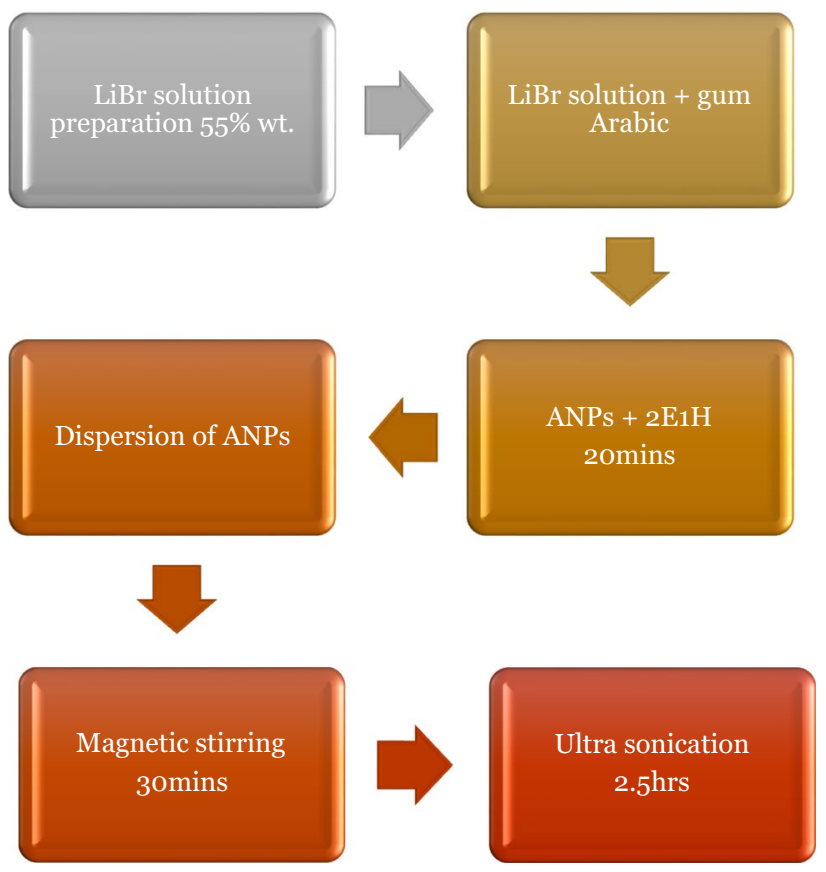

Fig. 1 Schematic nanofluid preparation by a two-step method [41]

ejector to investigate the key properties of refrigerant vapour entrainment and absorption. The results were assessed to estimate the parameters for understanding physical mechanisms of heat and mass transfer. The rig was designed as a close loop system as shown in Fig. 2, which runs within a designed operating conditions subjected to a test matrix (Figs. 3 and 4).

The rig consists of two solution tanks, both of which were connected to a variable speed pump operated at 3.0 bar pressure. A $3.0-\mathrm{kW}$ steam generator was installed to generate a low-pressure refrigerant vapour into the ejector, which is connected to an overhead water tank supplying water from $3 \mathrm{~m}$ above. The ejector was mounted on a rigid support $2.0 \mathrm{~m}$ height from ground level and $2.2 \mathrm{~m}$ width connected to the pump via a 0.5 -in. stainless steel pipe (316). The ejector discharge was connected to the inlets of the solution tanks. Pressure transducers, T-type thermocouples temperature sensors, mass flow metres, and conductivity sensors were inserted in the pipelines
Table 1 Sample solutions description

\begin{tabular}{lll}
\hline Sample description & Composition \\
\hline S1 & Reference solution no HTA no NP & $\mathrm{LiBr} / \mathrm{H}_{2} \mathrm{O}$ \\
S2 & Nanofluid without HTA & $\mathrm{LiBr} / \mathrm{H} 20+\mathrm{Al} 2 \mathrm{O} 3 \mathrm{NP}(\mathrm{LiBr}-\mathrm{ANF})$ \\
S3 & Nanofluid with HTA & $\mathrm{LiBr} / \mathrm{H} 2 \mathrm{O}+\mathrm{Al} 2 \mathrm{O} 3$ \\
& & $\mathrm{NP}+\mathrm{GA}+2 \mathrm{E} 1 \mathrm{H}(\mathrm{LiBr}-$ \\
& & ANF+HTA) \\
\hline
\end{tabular}

$H T A$ heat transfer additives, $N P$ nanoparticles, $G A$ gum Arabic, 2E1H 2-ethyl-1-hexanol 

an ejector-boosted absorption experimental test rig, where $\mathrm{P}$ is the Pump, EB for ejector booster, and SG for steam generator

Fig. 3 Image of prototype ejector adiabatic absorber fabricated by Transvac ltd
Fig. 2 Schematic layout for
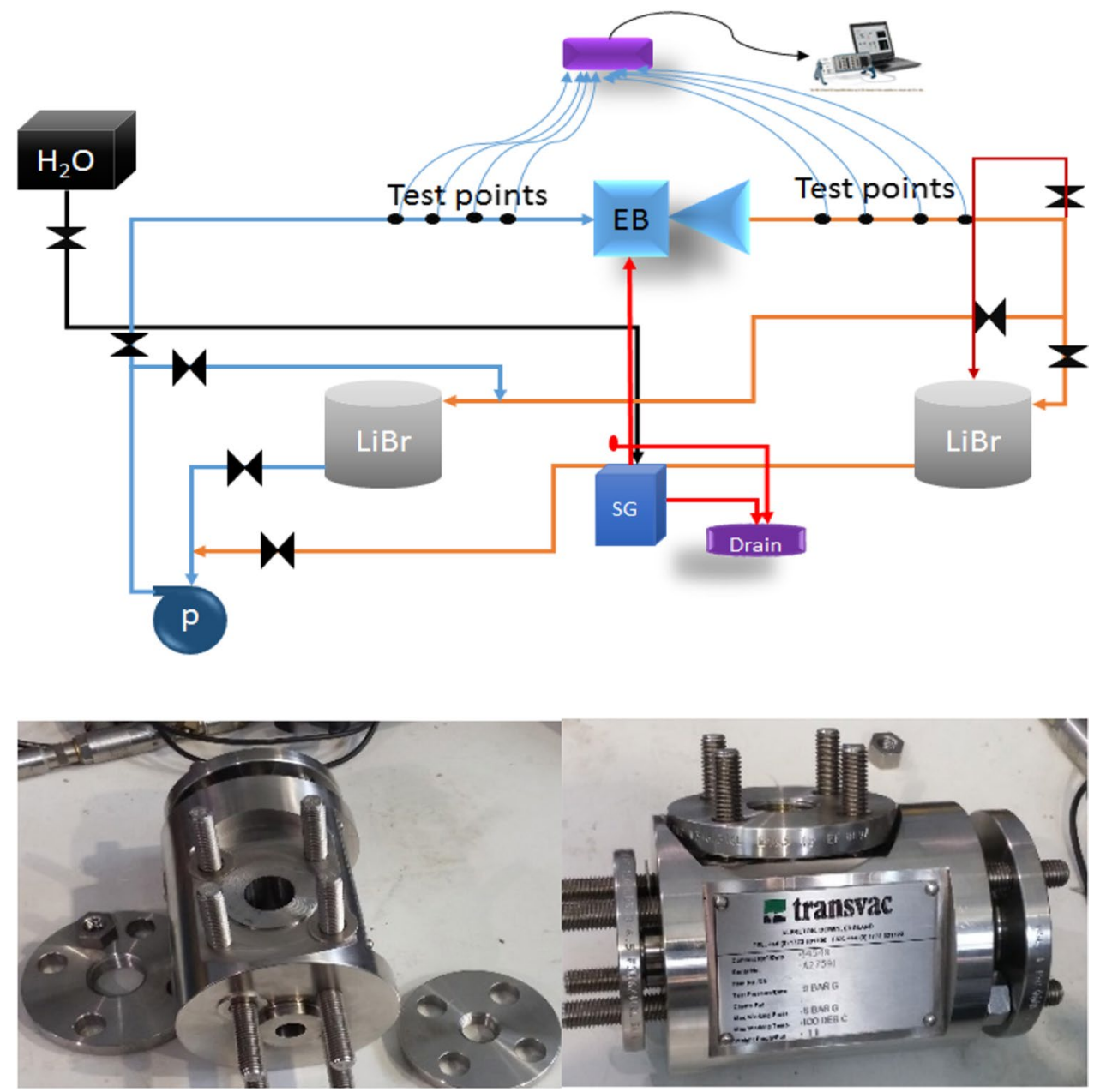

Fig. 4 Ejector adiabatic absorber experimental test rig
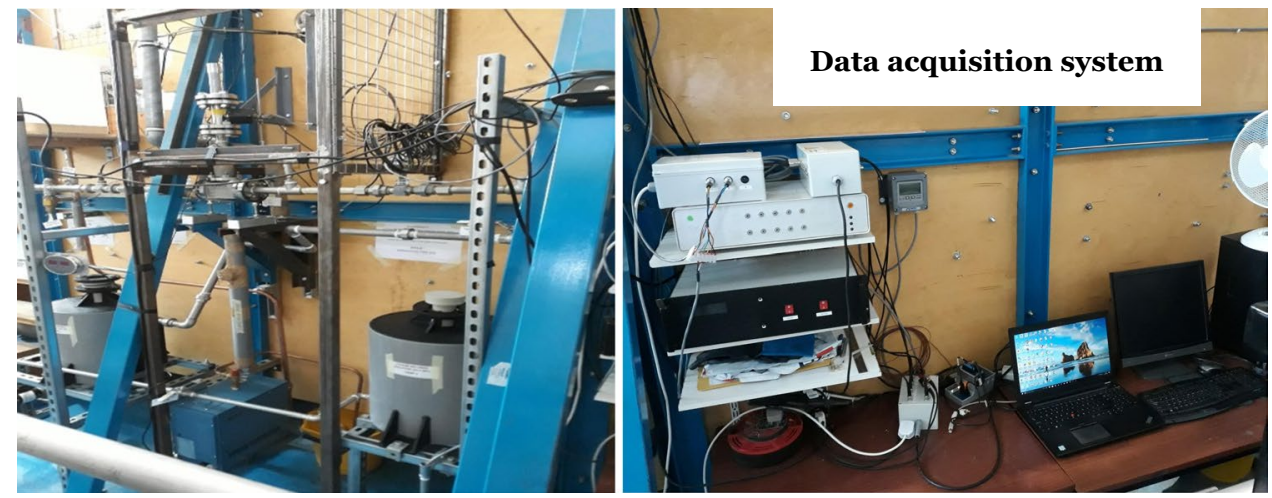

at both upstream and downstream of the ejector to record both input and output data. These sensors were connected to an instrumentation and control unit, which are finally connected to a data acquisition system. This transforms the sensor output signals to numerical values that can be further analysed for a wide range of parameters. The pressure relief valves were installed on the high-pressure side (upstream of the ejector) and on the steam generator for safety purposes (Table 2).

\subsection{Experimental procedure}

$\mathrm{LiBr} 55 \%$ wt solution and $\mathrm{H}_{2} \mathrm{O}$ were added into the $\mathrm{LiBr}$ tank-1 and an overhead water tank for steam generator respectively. When the valve connecting the solution tank-1 to the pump is switched on, the valve that connects the overhead water tank to the steam generator is also turned on simultaneously. A bypass was provided at the pump outlet before a flow control valve to return 
Table 2 The uncertainties of sensors used on the ejector experimental test rig

\begin{tabular}{lll}
\hline Sensor type & Measurement & Uncertainty \\
\hline Coriolis mass flow metre & Mass flowrate of solution and refrigerant & $\pm 0.101 \%$ of reading (20 to 1) \\
Electrical conductivity probes & Concentration of solution & $\pm 0.3 \%$ of reading (20 to 1) \\
Pressure transducers & Pressure of solution and refrigerant & $\pm 0.25 \%$ of reading (20 to 1) \\
$\begin{array}{l}\text { T-type thermocouples tempera- } \\
\text { ture sensors }\end{array}$ & Temperature of solution and refrigerant & $\pm 0.28{ }^{\circ} \mathrm{C}$ (20 to 1) \\
\hline
\end{tabular}

excess flow back into the solution tank. The weak solution discharged from the ejector has two possible return tanks depending on whether one needs only to measure the solution conductivity in the pipe or in the tank at the end of each run; therefore, the valves are turned on and off as appropriate.

The steam generator is first switched on as it takes about $3 \mathrm{~min}$ for the vapour to be generated to the ejector. The solution pump is subsequently switched on to provide the desired flow rate setting. The solution flows into the ejector at pressure $P_{p}$ (bar), temperature $T_{p}(\mathrm{~K})$, mass flow rate $\dot{m}_{p}(\mathrm{~kg} / \mathrm{s})$, and conductivity $C_{p}(\mathrm{mS} / \mathrm{cm})$ were measured. The ejector circulation is operated efficiently to be able to entrain and mix the solution with the vapour generated in the system. The resulting values of pressure $P_{d}(\mathrm{bar})$, temperature $T_{d}(\mathrm{~K})$, mass flow rate $\dot{m}_{d}(\mathrm{~kg} / \mathrm{s})$, and conductivity $C_{d}(\mathrm{mS} / \mathrm{cm})$ were also collected using their respective sensors. Signal outputs from the sensors are transmitted through a data acquisition card to a "LabView" system where readable data files are obtained for processing. The testing of $\mathrm{LiBr}$ solution only had served as a baseline for the comprehensive analysis of the new binary nanofluid prepared, LiBr-ANF with HTA. Lee et al. [22] originally proposed this working fluid recipe, which was considered in this article for investigation covering ejector-boosted absorption system.

\subsection{Governing equations}

The experimental results were obtained from the series of trial run under different operating conditions using the ejector test rig. The data were analysed and evaluated focussing on the energy, solution concentration, heat, and mass transfer equations that are based on the following equations.

Thermal energy equation

$Q=\dot{m} C p \Delta T[22]$

Energy balance equation

$$
\begin{gathered}
Q=\dot{m}_{c . i n} C p_{c}\left(T_{c . o u t}-T_{c . i n}\right)=\dot{m}_{\text {sol.p }} H_{\text {sol. }} \\
-\dot{m}_{\text {sol.d }} H_{\text {sol.d }}+\Delta \dot{m}_{a r} H_{v}
\end{gathered}
$$

Mass balance equation $\dot{m}_{\text {sol. } p}+\Delta \dot{\boldsymbol{m}}_{a r}=\dot{\boldsymbol{m}}_{\text {sol.d }}[22]$

Solution concentration balance

$\boldsymbol{x}_{p} \dot{\boldsymbol{m}}_{\text {sol.p }}=\boldsymbol{x}_{d} \dot{\boldsymbol{m}}_{\text {sol.d }}[22]$

Heat transfer equations

$Q=U A \Delta T_{L M}[22]$

Where

$\boldsymbol{U A}=\boldsymbol{h}_{c} \boldsymbol{A}_{c}+\frac{1}{\boldsymbol{R}_{w}}+\boldsymbol{h}_{\text {sol }} \boldsymbol{A}_{\text {sol }}$ [22]

And,

$\Delta T_{L M}=\frac{\left(T_{\text {solp }}-T_{\text {cout }}\right)-\left(T_{\text {sold }}-T_{\text {c.in }}\right)}{\ln \left[\left(T_{\text {solp }}-T_{\text {c.out }}\right) /\left(T_{\text {sold }}-T_{\text {c.in }}\right)\right]}[22]$

This equation can be reframed since in this case there is no coolant.

$\Delta T_{L M}=\frac{\left(T_{\text {sol. }}\right)-\left(T_{\text {sol. }}\right)}{\ln \left[\left(T_{\text {solp }}\right) /\left(T_{\text {sol. } d}\right)\right]}$

So, for the mass transfer equation we have

$\Delta \dot{m}_{a r}=\beta \rho A \Delta T_{L M}[22]$

Also,

$\Delta \boldsymbol{T}_{L M}=\frac{\left(x_{p}^{e q}-x_{p}\right)-\left(x_{d}^{e q}-x_{d}\right)}{\ln \left[\left(x_{p}^{e q}-x_{p}\right) /\left(x_{d}^{e q}-x_{d}\right)\right]}[22]$

All symbols are defined in the Nomenclature section.

The ejector was customised for minimum pressure loss, and this is evident from the pressure results recorded in Table 3. This provides the ejector with both absorption and recompression characteristics at the same time.

\subsection{Uncertainty analysis}

Equations 1 to 10 can only be calculated based on the independent measured variables: temperature, pressure, electrical conductivity, and mass flowrate of the solution and refrigerant. The measurement of uncertainty contributing to the performance metrics of the absorption, heat, and mass 
Table 3 Data from ejector test rig for different parameters

\begin{tabular}{llllllll}
\hline$\dot{m}_{\text {sol. } p}(\mathrm{~kg} / \mathrm{s})$ & $\dot{m}_{\text {sol. }}(\mathrm{Kg} / \mathrm{s})$ & $x_{p}(\%)$ & $x_{d}(\%)$ & $P_{p}(\mathrm{bar})$ & $P_{d}(\mathrm{bar})$ & $T_{p}(\mathrm{~K})$ & $T_{d}(\mathrm{~K})$ \\
\hline 0.051 & 0.0517 & 55 & 54.3 & 2.98 & 1.94 & 292.6 & 291.9 \\
0.068 & 0.0685 & 54 & 53.6 & 3.01 & 1.97 & 293.6 & 292.8 \\
0.085 & 0.0864 & 53.5 & 52.6 & 3 & 2.08 & 294.4 & 293.6 \\
0.102 & 0.1036 & 52.5 & 51.7 & 3.01 & 2.1 & 295.3 & 294.5 \\
0.119 & 0.1208 & 51.7 & 50.9 & 3.01 & 2.1 & 296.2 & 295.4 \\
0.136 & 0.138 & 50.9 & 50.1 & 3.02 & 2.09 & 297.1 & 296.3 \\
0.153 & 0.155 & 50.1 & 49.5 & 3 & 2.11 & 298.0 & 297.1 \\
0.17 & 0.1722 & 49.4 & 48.8 & 3 & 2.12 & 298.9 & 298.0 \\
\hline
\end{tabular}

transfer rates can be computed by Kline and McKlintock technique [42].

The uncertainty in absorption rate measurement from Eq. 3 can drive as follows:

$\Delta \dot{m}_{a r}=\dot{m}_{\text {sol.d }}-\dot{m}_{\text {sol.p }}$

$u_{\Delta \dot{m}_{a r}}= \pm\left[\left(\frac{\boldsymbol{m}_{\text {sol.d }}}{\Delta \dot{m}_{a r}} \frac{\partial \Delta \dot{m}_{a r}}{\partial \boldsymbol{m}_{\text {sol.d }}} \boldsymbol{u}_{\boldsymbol{m}_{\text {sol.d }}}\right)^{2}+\left(\frac{\boldsymbol{m}_{r e f .}}{\Delta \dot{m}_{a r}} \frac{\partial \Delta \dot{m}_{a r}}{\partial \dot{m}_{\text {sol.p }}} \boldsymbol{u}_{\dot{m}_{\text {sol. }}}\right)^{2}\right]^{\frac{1}{2}}$

where,

$\dot{m}_{s o l . d}=\frac{\Delta m_{d}}{\Delta t}$

$\Delta m_{d}=m_{\text {sol. }}+m_{r e f}$

$u_{\Delta m_{d}}= \pm\left[\left(\frac{m_{s o l .}}{\Delta m_{d}} \frac{\partial \Delta m_{d}}{\partial m_{s o l .}} u_{m_{\text {sol. }}}\right)^{2}+\left(\frac{\boldsymbol{m}_{r e f .}}{\Delta m_{d}} \frac{\partial \Delta \boldsymbol{m}_{d}}{\partial m_{r e f .}} u_{m_{r e f .}}\right)^{2}\right]^{\frac{1}{2}}$

$u_{\dot{m}_{\text {sol.d }}}= \pm\left[\left(\frac{\Delta \boldsymbol{m}_{d}}{\dot{\boldsymbol{m}}_{\text {sol.d }}} \frac{\partial \dot{\boldsymbol{m}}_{\text {sol.d.d }}}{\partial \Delta \boldsymbol{m}_{d}} \boldsymbol{u}_{\Delta \boldsymbol{m}_{d}}\right)^{2}+\left(\frac{\Delta t}{\dot{\boldsymbol{m}}_{\text {sol.d }}} \frac{\partial \dot{\boldsymbol{m}}_{\text {sol.d }}}{\partial \Delta t} \boldsymbol{u}_{\Delta t}\right)^{2}\right]^{\frac{1}{2}}$

$\dot{m}_{\text {sol.p }}=\frac{\Delta m_{\text {sol.p }}}{\Delta t}$

$\boldsymbol{u}_{\dot{m}_{\text {sol. }}}= \pm\left[\left(\frac{\Delta \boldsymbol{m}_{\text {sol. } p}}{\dot{\boldsymbol{m}}_{\text {sol. } p}} \frac{\partial \dot{\boldsymbol{m}}_{\text {sol. } p}}{\partial \Delta \boldsymbol{m}_{\text {sol. } p}} \boldsymbol{u}_{\Delta \boldsymbol{m}_{\text {sol. } p}}\right)^{2}+\left(\frac{\Delta t}{\dot{\boldsymbol{m}}_{\text {sol. } p}} \frac{\partial \dot{\boldsymbol{m}}_{\text {sol. } p}}{\partial \Delta t} \boldsymbol{u}_{\Delta t}\right)^{2}\right]^{\frac{1}{2}}$

Solution concentration measurement uncertainty can be calculated using Eq. 19 from Eq. 4.
Heat transfer measurement uncertainty

$\boldsymbol{u}_{\boldsymbol{Q}}= \pm\left[\left(\frac{\partial \boldsymbol{Q}}{\partial \boldsymbol{U} \boldsymbol{A}} \boldsymbol{u}_{U A}\right)^{2}+\left(\frac{\partial \boldsymbol{Q}}{\partial \Delta \boldsymbol{T}_{L M}} \boldsymbol{u}_{\Delta T_{L M}}\right)^{2}\right]^{\frac{1}{2}}$

The mass transfer measurement uncertainty

$\Delta \dot{m}_{a r}=\beta \rho A \Delta \boldsymbol{T}_{L M}= \pm\left[\left(\frac{\boldsymbol{m}_{\text {sol.d. }}}{\Delta \dot{m}_{\text {ar }}} \frac{\partial \Delta \dot{m}_{a r}}{\partial \boldsymbol{m}_{\text {sol. } .}} \boldsymbol{u}_{m_{\text {sol.d }}}\right)^{2}+\left(\frac{\boldsymbol{m}_{r e f .}}{\Delta \dot{m}_{a r}} \frac{\partial \Delta \dot{m}_{a r}}{\partial \dot{m}_{\text {sol. } p}} u_{i_{\text {sol. }}}\right)^{2}\right]^{\frac{1}{2}}$

Unlike the total uncertainty for SCB and MB, the uncertainties in temperature and time interval between measurements have the most significant contribution to the total uncertainty results obtained for absorption, heat, and mass transfer rates. The experiment was conducted with a very high precision, repeatability, and reproducibility (Fig. 5).

\section{Results and discussion}

Following the preparation of samples and the experimental test rig setup, each sample was run in the rig and the experimental data collected as shown in Table 3 to calculate and study other parameters. The resulting absorption rate, MTC, HTR and HTC were obtained. Solution concentration change and the material mass balance were also reported. Figure 6 presents experimental results of vapour absorption rate of samples in an ejector adiabatic absorber.

It is clear from Figs. 6 and 7 that, with the addition of HTA, absorption rate and MTC increase significantly. The absorption rate gives optimum values across all flow rates for sample 3 containing HTA, which can be explained from the enhanced Gibbs-Marangoni effect. The surfactant allows a significant reduction in surface tension, which

$u_{x_{d} \dot{m}_{\text {sold }}}= \pm\left[\left(\frac{\Delta x_{d}}{x_{d} \dot{m}_{\text {sol.d }}} \frac{\partial x_{d} \dot{m}_{\text {sol.d }}}{\partial \Delta x_{d}} u_{\Delta x_{d}}\right)^{2}+\left(\frac{\Delta t}{x_{d} \dot{m}_{\text {sol.d }}} \frac{\partial x_{d} \dot{m}_{\text {sol.d }}}{\partial \Delta t} u_{\Delta t}\right)^{2}+\left(\frac{\Delta m_{d}}{x_{d} \dot{m}_{\text {sol.d }}} \frac{\partial x_{d} \dot{m}_{\text {sol.d }}}{\partial \Delta \boldsymbol{m}_{d}} u_{\Delta m_{d}}\right)^{2}+\left(\frac{\Delta t}{x_{d} \dot{m}_{\text {sol.d }}} \frac{\partial x_{d} \dot{m}_{\text {sol.d }}}{\partial \Delta t} u_{\Delta t}\right)^{2}\right]^{\frac{1}{2}}$ 
Fig. 5 Plots of total calculated uncertainty in each measurement in the experiments, where $\mathrm{SCB}$ is the solution concentration balance, $\mathrm{MB}$ is mass balance, HT is heat transfer, MT is mass transfer, and Abs. rate is absorption rate

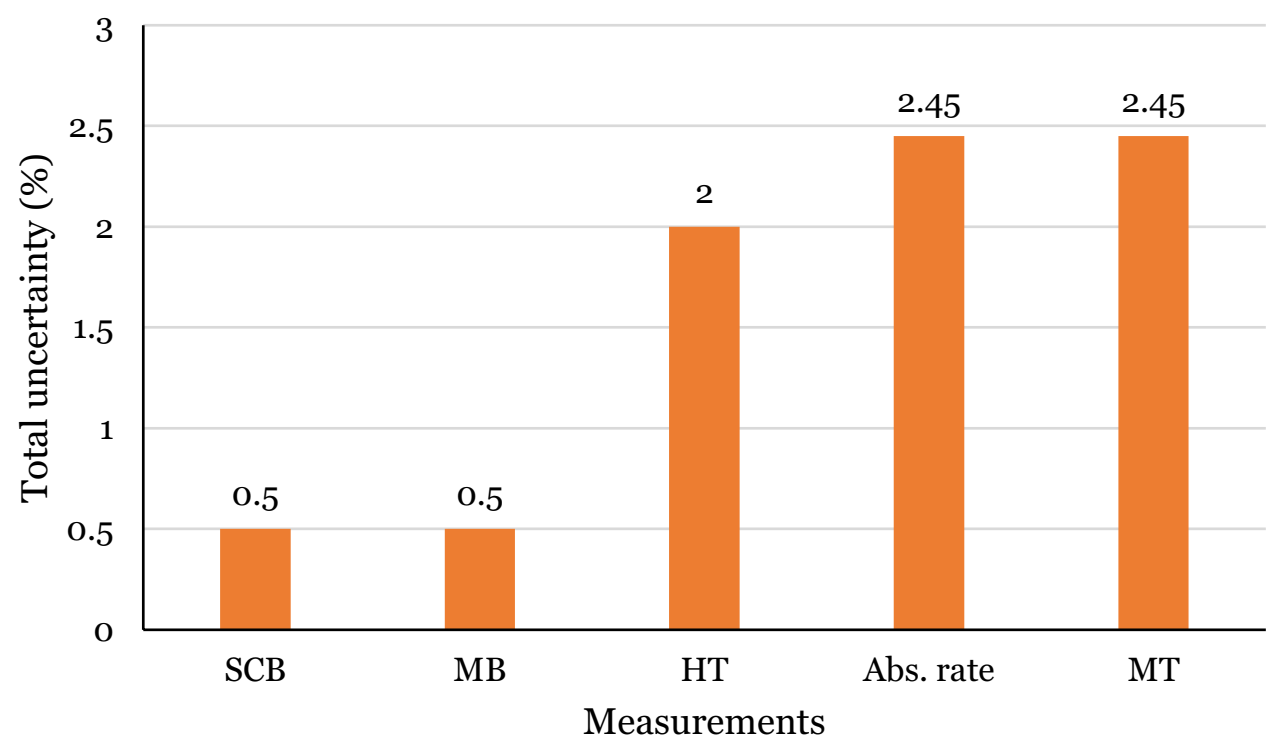

Fig. 6 Nanofluid testing: absorption rate against solution mass flowrate. $\mathrm{LiBr}$ solution: aqueous lithium bromide solution 55\% wt. LiBr-ANF: lithium bromide-alumina nanofluid. LiBr-ANF+ HTA: lithium bromide-alumina nanofluid with heat transfer additives

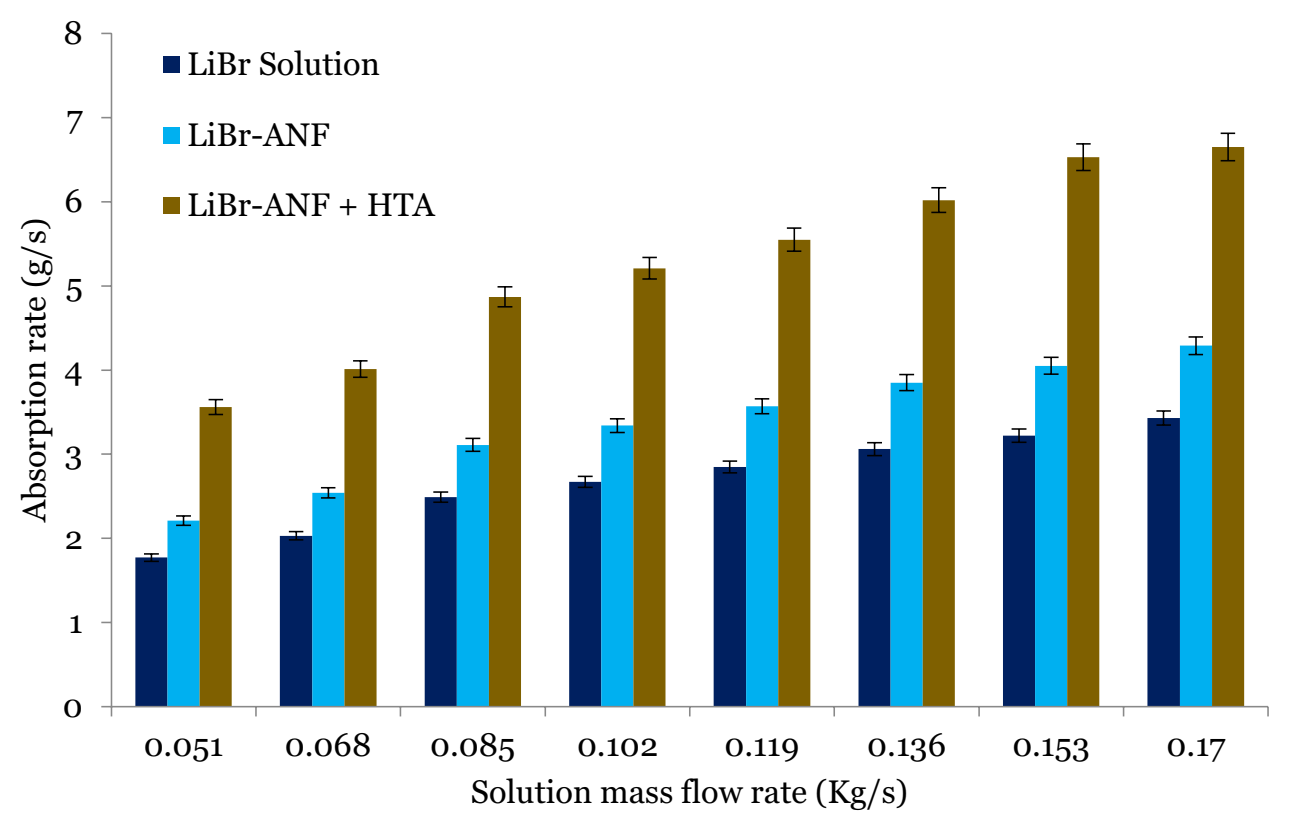

enables absorption of more refrigerant vapour. In ejector adiabatic absorption, the refrigerant vapour is absorbed by the solution itself at the exit of the primary nozzle (inlet section), and it is also entrained into solution channel at the mixing chamber by the high-pressure solution. The combined effect exhibited by this flow system gives it an edge over a conventional adiabatic absorber, which primarily relies only on the ability of solution to absorb refrigerant vapour through falling film absorption mechanism.

The HTR and HTC of the samples from the ejector adiabatic absorber test rig show a steady increase in values as heat is transferred from the evaporator (in this case the suction line) to the ejector discharge section with increasing solution mass flowrate more than what was reported earlier by Lee et al. [22]. This implies that the ability of ejectors to reabsorb rejected heat from a thermal system back into the solution is enormous. The higher the mass flowrate, the larger the surface area for heat and mass transfer, and the greater the waste heat or refrigerant vapour entrained into the ejector mixing chamber. However, beyond the designed flowrate of the ejector, choking occurs at the throat or mixing chamber, thereby causing a decrease in rate of heat and mass transfer (Figs. 8 and 9).

The HTR and HTC of sample 3 having HTA are higher compared to those without HTA. However, in both cases, samples 2 and 3 containing ANPs show a significant increase when compared to sample 1 without ANPs. This shows the significant impact of nanoparticle dispersion to 
Fig. 7 Nanofluid testing: mass transfer coefficient against solution mass flowrate

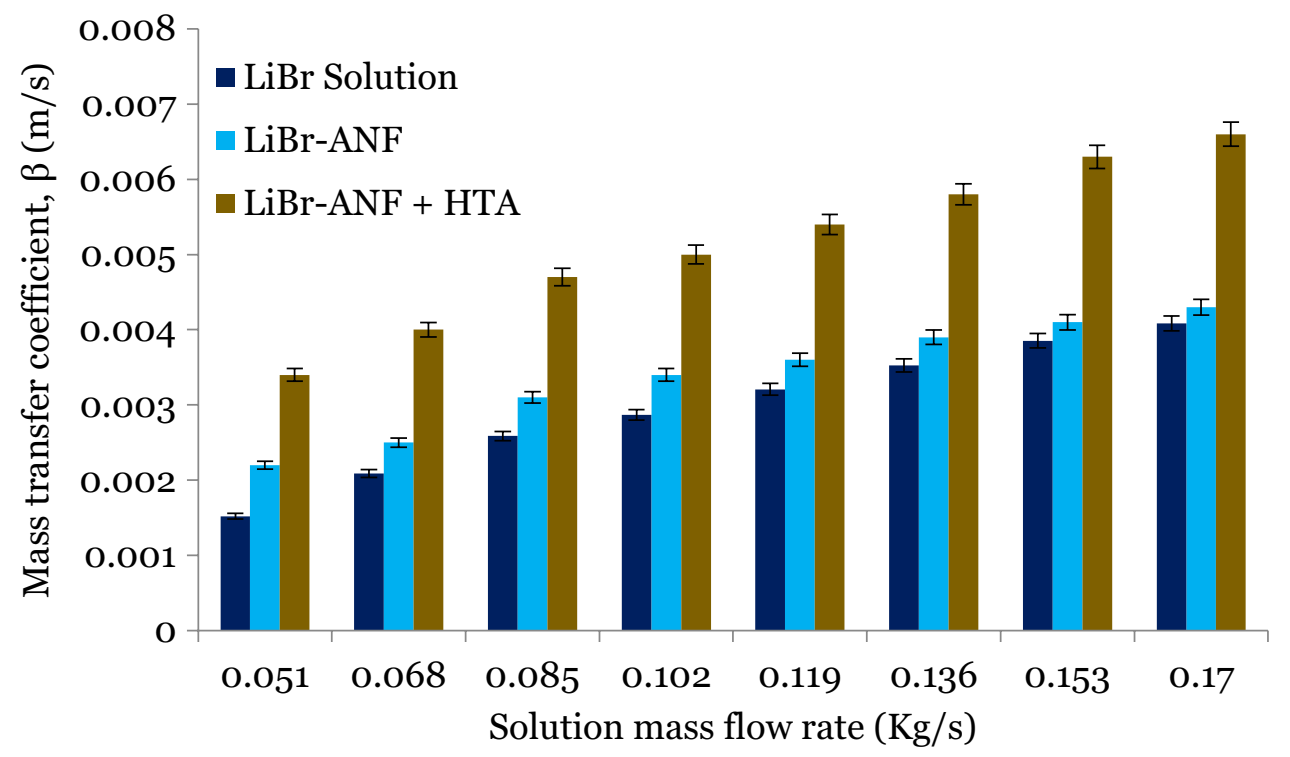

Fig. 8 Nanofluid testing: heat transfer rate against solution mass flowrate

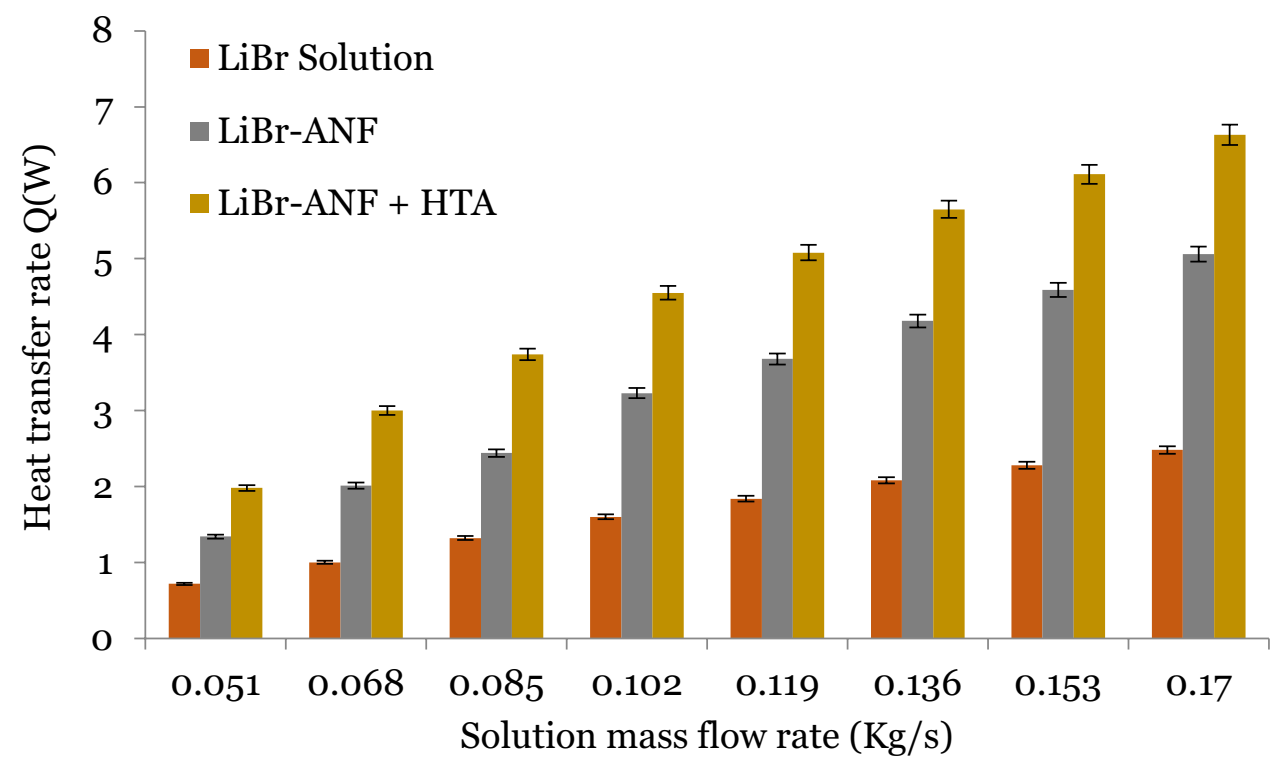

HTR and HTC of a base fluid. This phenomenon is different in the case of absorption rate and MTC where only the addition of HTA presented a large increase, which is earlier explained.

The nature of material mass balance results presented in Fig. 10 can be explained in accordance with Eq. 3. It implies that the refrigerant vapour from the evaporator and concentrated solution from the generator enter into the ejector where both streams mix and form a dilute solution at the discharge. The solution mass flow balance reveals that across all the operating flow rates, about $99.5 \%$ of the mass inflow of refrigerant vapour and concentrated solution is recovered as mass outflow at the discharge of the ejector, i.e. as dilute solution, which is expected. The degree of dilution of the solution tells us about the extent of the refrigerant vapour absorbed into the solution in the absorber.

The solution concentration decreases with increasing absorption rate, which is a function of solution mass flow rate as shown in Fig. 11. The concentrated solution dilutes as soon as it exits the primary nozzle, and dilution becomes higher with more entrained vapour in the mixing chamber. Since the solution recirculates three times before leaving the absorber to the generator, the solution becomes more diluted and weaker in concentration as it finally gets into the generator. This dilution of the concentrated solution is what is always expected, indicating the amount of refrigerant vapour absorbed. 
Fig. 9 Nanofluid testing: heat transfer coefficient against solution mass flowrate
Fig. 10 Material mass flow rate against solution mass flowrate
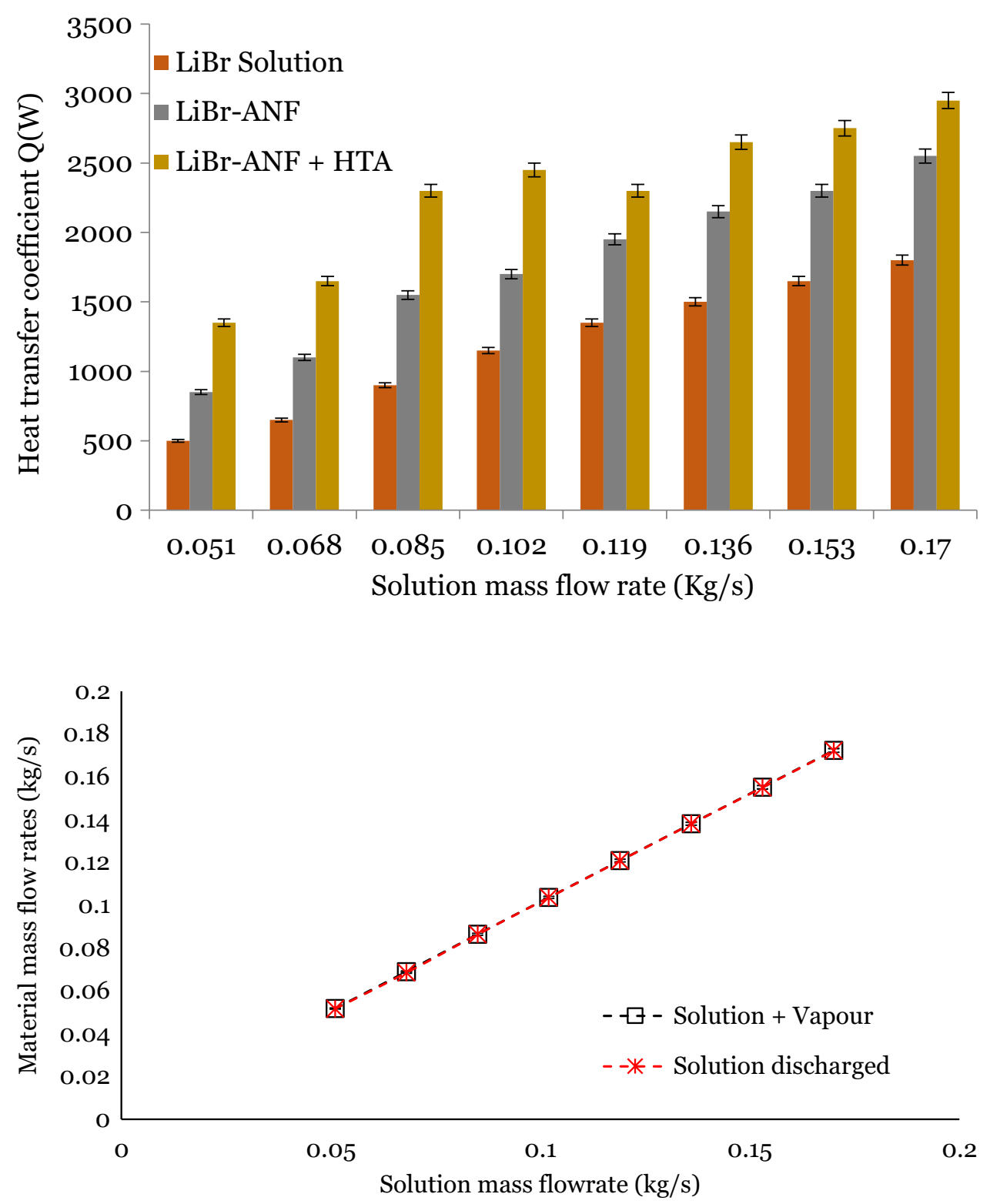

\subsection{Enhancement analysis}

Enhancement analysis was conducted with results from the most stable operating flowrate within the results reported, which is $0.085 \mathrm{~kg} / \mathrm{s}$. The percentage enhancement in absorption rate, MTC, HTR, and HTC between the three samples was computed and presented in Fig. 12. Absorption rate recorded enhancements of $25 \%, 96 \%$, and $57 \%$ with nanoparticles, nanoparticles + HTA, and HTA addition respectively. MTC recorded enhancements of $20 \%, 82 \%$, and $52 \%$ for the same samples. These enhancement values obtained by the addition of nanoparticles for both parameters were solely due to entrainment of refrigerant vapour as a result of increase in density of the fluid. It could be seen that enhancements for both parameters tripled when nanoparticles and
HTA were added compared to that when only nanoparticles were added. This is because as more refrigerant is entrained due to density difference, the sample (En - NPs + HTA) containing HTA also enhances absorption and mass transfer through Gibbs-Marangoni effect. Similarly, in the sample (En-HTA), enhancements were solely due to reduction in surface tension of the solution leading to Gibbs-Marangoni effect, since both samples contain ANPs. There is no density difference in this case. However, a slight viscosity increase may be present, which has no effect on absorption rate and mass transfer coefficient.

On the other, the ejector adiabatic absorber presents a remarkable percentage enhancement of HTR and HTC in all the three samples. The HTR recorded enhancements of $85 \%, 183 \%$, and $53 \%$ for samples with nanoparticles, 
Fig. 11 Solution concentration (\%) against absorption rate $(\mathrm{g} / \mathrm{s})$

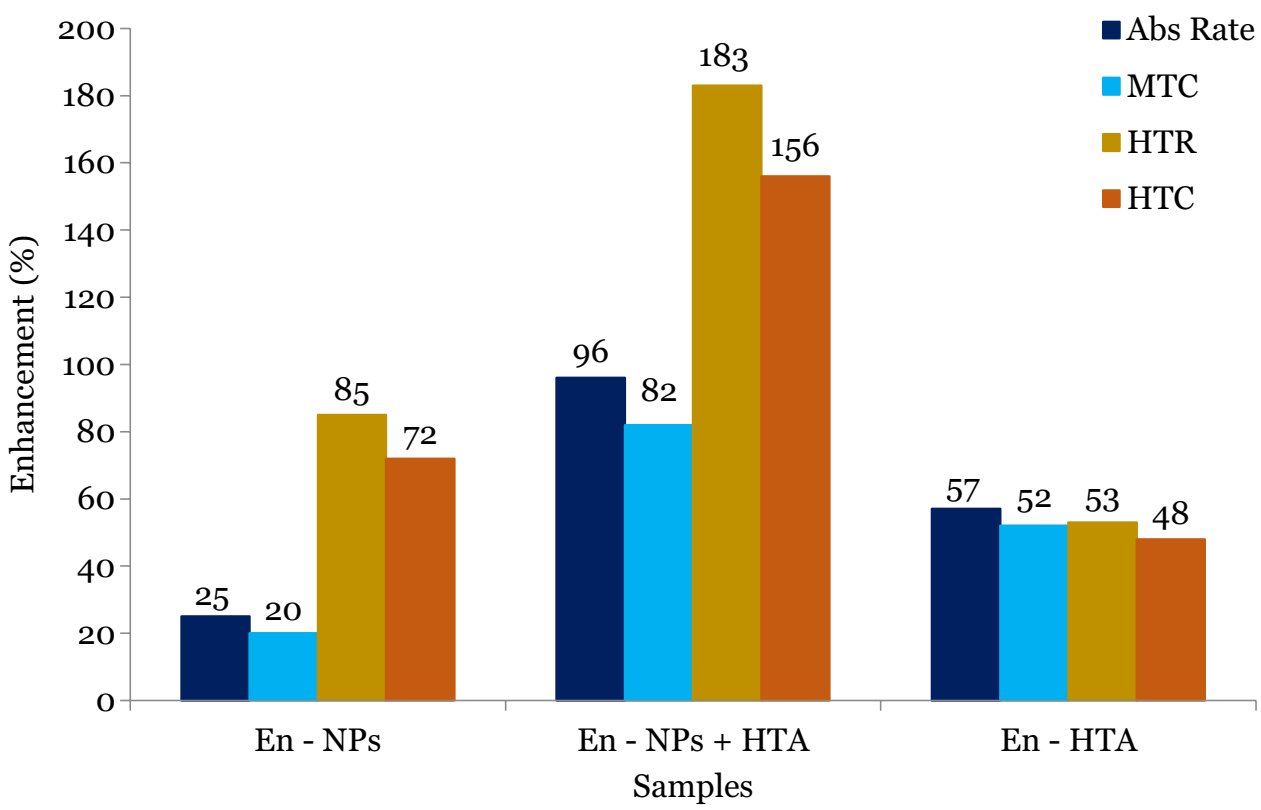

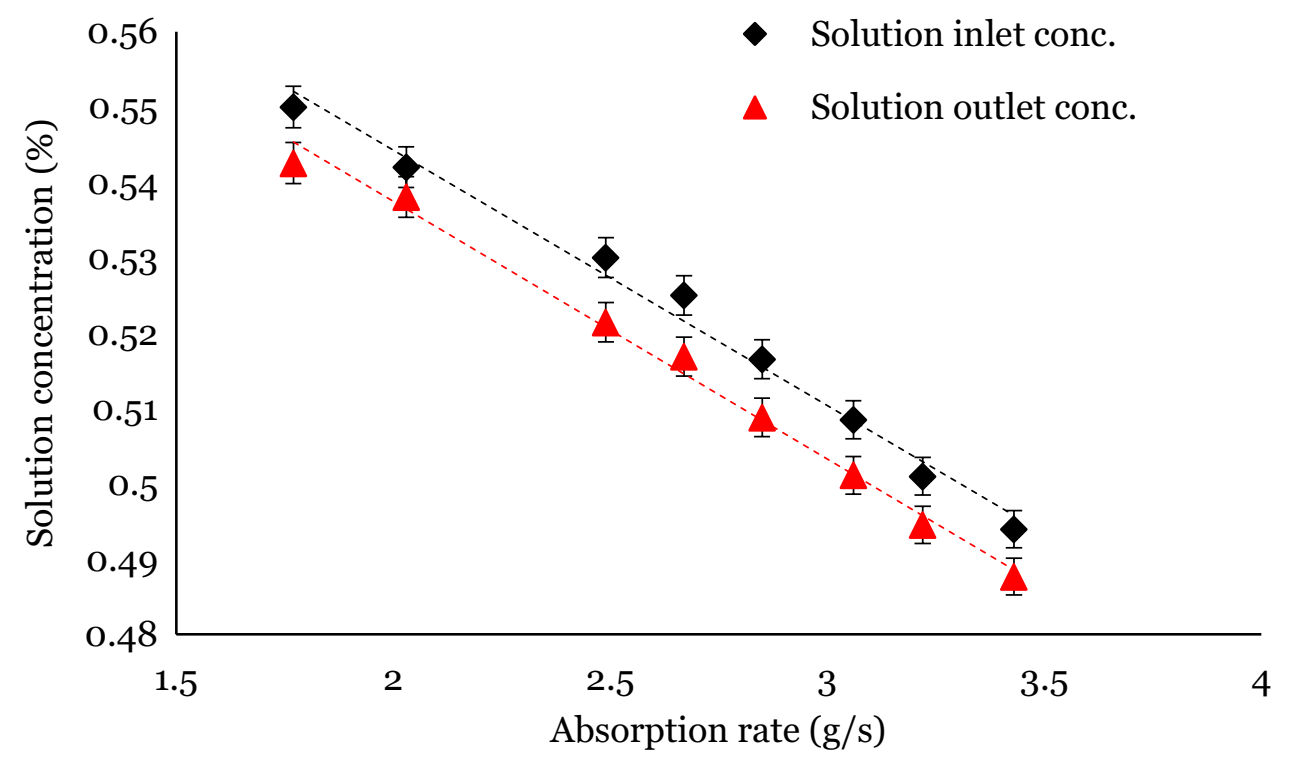

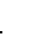

Fig. 12 Percentage enhancement results obtained between the three samples for absorption rate (Abs Rate), mass transfer coefficient (MTC), heat transfer rate (HTR), and heat transfer coefficient (HTC), where En - NPs is the enhancement due to addition of nanoparticles to LiBr solution, En - NPs + HTA is the enhancement due to addition of nanoparticles and heat transfer additives to $\mathrm{LiBr}$ solution, and En - HTA is the enhancement due to addition heat transfer additives to $\mathrm{LiBr}$ ANF 
Fig. 13 Relative values for the three samples for absorption rate (Abs Rate), mass transfer coefficient (MTC), heat transfer rate (HTR), and heat transfer coefficient (HTC), where En - NPs is the enhancement due to addition of nanoparticles to LiBr solution, En - NPs + HTA is the enhancement due to addition of nanoparticles and heat transfer additives to $\mathrm{LiBr}$ solution, and En - HTA is the enhancement due to addition heat transfer additives to $\mathrm{LiBr}$ ANF

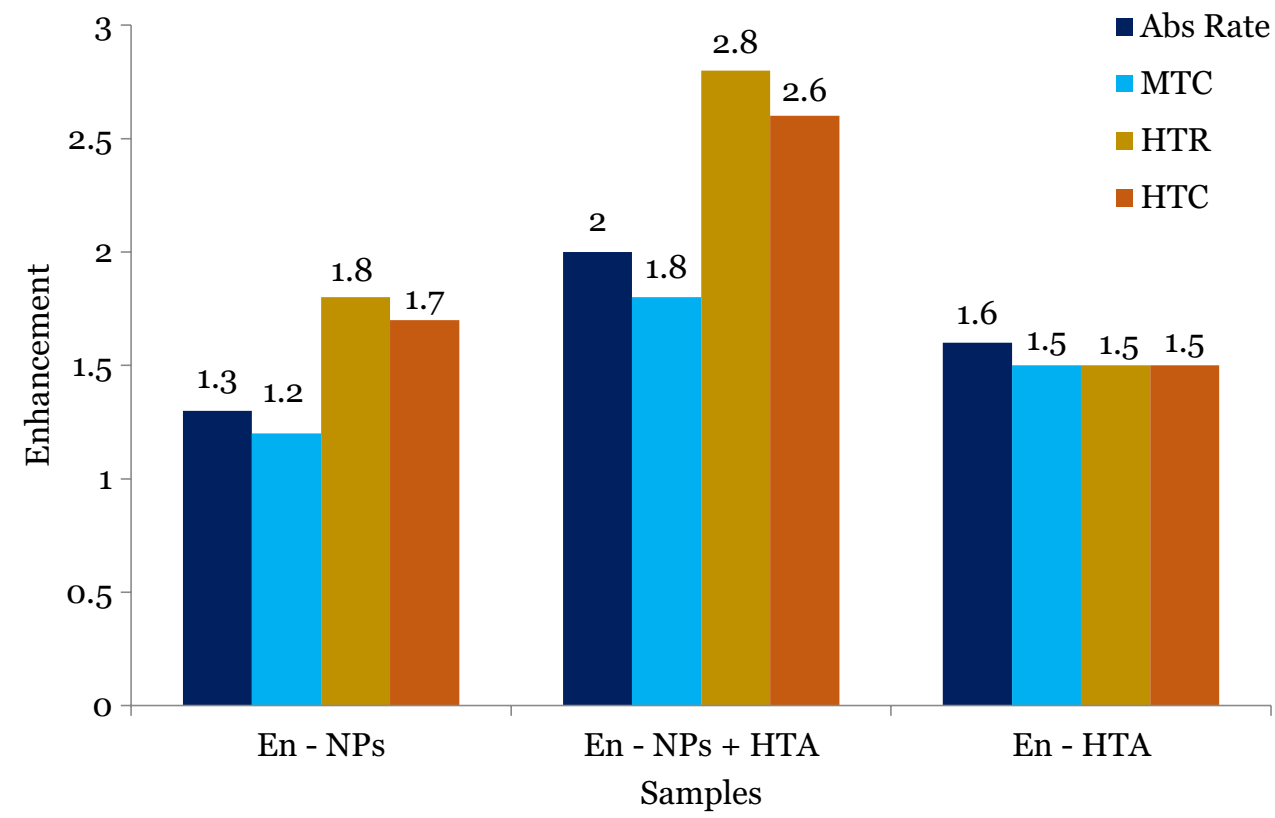

higher value than the reference sample. Therefore, parameters with relative values of $\geq 2$ mean that the sample is twice the value of the reference sample. In Fig. 13, it can be seen that the HTR has a relative value of 1.8 for LiBrANF with reference to the $\mathrm{LiBr}$ solution, which means it has twice the HTR of LiBr solution sample. Similarly, the LiBr-ANF + HTA sample has twice the relative values of the reference sample for all the parameters analysed.

The addition of gum Arabic is highly significant as a stabilising agent. Gum Arabic allows keeping the nanoparticles in a uniform suspension making fluid stable. It is possible that gum Arabic reduces the heat and mass transfer rates. This decrease is due to three factors, namely:

1) increase in viscosity of the fluid,

2) decrease in mobility or speed of nanoparticles, and

3) decrease in "effective collision" between nanoparticles.

Gum Arabic is a high molecular weight organic compound containing mainly polysaccharides and some percentage of protein, which when dissolved in the solution increases the viscosity of the fluid. Since this fluid is pumped through the ejector adiabatic absorber, it passes through a constricted nozzle and throat (mixing tube), which are about three times smaller in diameter than the main pipe through which the fluid flows. Thus, increase in viscosity leads to increase inflow restriction, consequently decreasing entrainment of the secondary fluid (refrigerant vapour), thereby decreasing absorption, heat and mass transfer rates. Secondly, when gum Arabic dissolves, the sugar polymer and protein molecules adsorb to the surface of the nanoparticles thereby forming protein and sugar polymer layers. This allows the nanoparticles to be suspended at a relatively fixed position with limited movement. Thirdly, these protein and sugar polymer layers formed on the nanoparticles increases their size reduce their speed and direct contact. Because of the layer formed, there is no longer an effective and direct collision among particle surfaces. Gum Arabic has an adverse effect on nanofluid performance by hindering its thermal property, a limit on particle movement and entrainment potential for the nanoparticle flowrate that should be taken into account for the selection of constituent materials of nanofluid. This has been the reason why the new synthesis procedure presented in Fig. 1 was adopted. The method mitigates the aforementioned phenomenon of gum Arabic effects through surface functionalization of nanoparticles with surfactant and was developed by Muhammad et al. [41].

The enhancements obtained from ejector-boosted absorption system under the same operating conditions such as flowrate $(0.054 \mathrm{~kg} / \mathrm{s})$ are significantly higher than the enhancement recorded from a falling film absorption system. The ejector high entrainment capability is responsible for the augment in percentage enhancements obtained.

\section{Conclusion}

In an attempt to study the efficacy of an ejector adiabatic absorber for heat and mass transfer in an absorption system, a custom-made ejector with minimum pressure loss was used with a novel working fluid ( $\mathrm{LiBr}-\mathrm{ANF}+\mathrm{HTA}$ ) already experimented on a falling film absorber for the purpose of comparison. To conclude on the effects of ejector adiabatic absorber on the binary nanofluid based on the experimental 
Table 4 Comparison of percent enhancement in Abs. rate, MTC, HTR and HTC for falling film absorption (literature by Lee et al. [22]) and ejector-boosted absorption (this work) at $0.054 \mathrm{~kg} / \mathrm{s}$ flowrate

\begin{tabular}{|c|c|c|c|}
\hline Parameters & $\begin{array}{l}\text { Literature (\% } \\
\text { enhancement) } \\
\text { Falling film } \\
\text { absorption Lee } \\
\text { et al. [22]. LiBr- } \\
\text { ANF+ HTA }\end{array}$ & $\begin{array}{l}\text { This work (\% } \\
\text { enhancement) } \\
\text { Ejector-boosted } \\
\text { absorption LiBr- } \\
\text { ANF + HTA }\end{array}$ & $\begin{array}{l}\% \text { difference in } \\
\text { favour of this } \\
\text { work }\end{array}$ \\
\hline Abs. rate & 65 & 68 & 3 \\
\hline MTC & 44 & 55 & 11 \\
\hline HTR & 19 & 48 & 29 \\
\hline HTC & 42 & 59 & 17 \\
\hline
\end{tabular}

results obtained, analysed, and discussed, the following conclusions were drawn.

1. When alumina nanoparticles were added to pure $\mathrm{LiBr}$ solution, relative enhancements of 1.3, 1.2, 1.8 and 1.7 were recorded for absorption rate, MTC, HTR and HTC respectively relative to the $\mathrm{LiBr}$ solution. These enhancements are a typical effect of the ejector absorber due to a slight increase in density with negligible increase in viscosity. As the density of the working fluid pumped into the ejector increases, the heat and refrigerant vapour entrainment also increases.

2. When HTA was added to LiBr-ANF, the relative enhancements were almost thrice for HTR (2.8) and HTC (2.6), while for the absorption rate and MTC recorded, 2 and 1.8 respectively are a huge enhancement in heat and mass transfer using the ejector adiabatic absorber when compared to that of a falling film absorber as presented in Table 4 .

3. The mass balance and solution concentration balance results presented in Figs. 10 and 11 respectively prove the ejector as an efficient adiabatic absorber. It means that the mass inflow is equal to the mass outflow of ejector at a different flowrate, which is also an indication that the absorption rate is not only due to the concentration of the solution, but also due to the effect of the ejector adiabatic absorber.

Finally, with the conclusions reached, the effects of ejector adiabatic absorber cannot be over emphasised in absorption heat transfer system. Its compact nature and the absence of movable parts can reduce both size and maintenance cost of an absorption machine. It high efficiency in heat and mass transfer and capability to utilise low heat can further provide high thermal efficiency $\left(C O P_{T}\right)$.
Funding The authors received financial support from EPSRC and Innovate UK to carry out this work under research grant 132401 (I-UK) and EP/P016316/1. In addition, UA Muhammad is a recipient of the Petroleum Technology Development Fund (PTDF) sponsoring his PhD programme.

\section{Declarations}

Conflict of interest The authors declare no competing interests.

Open Access This article is licensed under a Creative Commons Attribution 4.0 International License, which permits use, sharing, adaptation, distribution and reproduction in any medium or format, as long as you give appropriate credit to the original author(s) and the source, provide a link to the Creative Commons licence, and indicate if changes were made. The images or other third party material in this article are included in the article's Creative Commons licence, unless indicated otherwise in a credit line to the material. If material is not included in the article's Creative Commons licence and your intended use is not permitted by statutory regulation or exceeds the permitted use, you will need to obtain permission directly from the copyright holder. To view a copy of this licence, visit http://creativecommons.org/licenses/by/4.0/.

\section{References}

1. C.C. Chen, D. Lee, Smart sensors enable smart air conditioning control. Sensors 14(6), 11179-11203 (2014). https://doi.org/10. 3390/s140611179

2. C.C. Cheng, D. Lee, Enabling smart air conditioning by sensor development: a review. Sensors MDPI AG 16(12), 2028 (2016). https://doi.org/10.3390/s16122028

3. W.C. Whitman, W.M. Johnson, J.A. Tomczyk, E. Silberstein, Refrigeration and Air Conditioning Technology, Sixth edition (2009)

4. G.H. Hundy, A.R. Trott, T.C. Welch, Refrigeration and Air-Conditioning. Elsevier Ltd Fourth Edition (2008).https://doi.org/10. 1016/B978-0-7506-8519-1.X0001-1

5. https://www.iasa-web.org/tc05/43-air-conditioning-and-envir onmental-control. Accessed on 3 Aug 2018

6. ASHRAE (American Society of Heating Refrigerating and AirConditioning Engineers). Ashrae handbook: fundamentals, I-P Edition. ASHRAE J. (2009). https://doi.org/10.1039/c1cs15219j

7. H. Tim, BBC World Service, 50 things that made the modern economy. (2017). https://www.bbc.co.uk/news/business-39735 802. Accessed 25 Sept 2019

8. S. Ginestet, D. Marchio, Control tuning of a simplified VAV system: methodology and impact on energy consumption and IAQ. Energ. Buildings 42(8), 1205-1214 (2010). https://doi.org/10. 1016/j.enbuild.2010.02.011

9. J. Lung-Yue, T. Tun-Ping, Performance evaluation of a hybrid cooling system for electronic chips. Exp. Thermal Fluid Sci. 45, 155-162 (2013). https://doi.org/10.1016/j.expthermflusci.2012. 10.020

10. N. Aste, C. Del Pero, F. Leonforte, Active refrigeration technologies for food preservation in humanitarian context - a review. Sustainable Energy Technol. Assess. 22, 150-160 (2017). https:// doi.org/10.1016/j.seta.2017.02.014

11. M. Isaac, D.P. Van Vuuren, Modeling global residential sector energy demand for heating and air conditioning in the context of climate change. Energy Policy 37(2), 507-521 (2019). https://doi. org/10.1016/j.enpol.2008.09.051 
12. B.F. Yu, Z.B. Hu, M. Liu, H.L. Yang, Q.X. Kong, Y.H. Liu, Review of research on air-conditioning systems and indoor air quality control for human health. Int. J. Refrig (2009). https://doi. org/10.1016/j.ijrefrig.2008.05.004

13. Y. Bravo, M. Carvalho, L.M. Serra, C. Monne, S. Alonso, F. Moreno, M. Munoz, Environmental evaluation of dish-Stirling technology for power generation. Sol. Energy 86(9), 2811-2825 (2012). https://doi.org/10.1016/j.solener.2012.06.019

14. G. Mohan, U. Kumar, M.K. Pokhrel, A. Martin, A novel solar thermal polygeneration system for sustainable production of cooling, clean water and domestic hot water in United Arab Emirates: dynamic simulation and economic evaluation. Appl. Energy 167, 173-188 (2016). https://doi.org/10.1016/j.apenergy.2015.10.116

15. O. Kaynakli, K. Saka, F. Kaynakli, Energy and exergy analysis of a double effect absorption refrigeration system based on different heat sources. Energy Convers. Manage. 106, 21-30 (2015). https://doi.org/10.1016/j.enconman.2015.09.010

16. S.C. Pang, H.H. Masjuki, M.A. Kalam, M.A. Hazrat, Renew. Sustain. Energy Rev. 28, 836-847 (2013)

17. E. Torrella Alcaraz, Cold production. Polytechnic University of Valencia. (1996)

18. L. Labra, D. Juirez-Romero, J. Siqueiros, A. Coronas, D. Salavera, Measurement of properties of a lithium bromide aqueous solution for the determination of the concentration for a prototype absorption machine. Appl. Therm. Eng. 114, 1186-1192 (2017). https:// doi.org/10.1016/j.applthermaleng.2016.10.162

19 R. Peters, C. Korinth, J.U. Keller, Vapour-liquid equilibria in the system NH3 + H2O + LiBr. 2. Data correlation. J. Chem. Eng. Data 40(4), 775-783 (1995). https://doi.org/10.1021/je00020a010

20. S.F. Wilbert, W.J. Jerold, Refrigeration and air conditioning. (McGraw-Hill, 1986)

21. C. Amaris, M. Valles, M. Bourouis, Vapour absorption enhancement using passive techniques for absorption cooling/heating technologies: a review. Appl. Energy 231, 826-853 (2018). https://doi.org/10.1016/j.apenergy.2018.09.071

22. J.K. Lee, H. Kim, H.K. Myung, J. Koo, Y.T. Kang, The effect of additives and nanoparticles on falling film absorption performance of binary nanofluids $\left(\mathrm{H}_{2} \mathrm{O} / \mathrm{LiBr}+\right.$ nanoparticles $)$. J. Nanosci. Nanotechnol. 9(12), 7456-7460 (2009). https://doi.org/10.1166/ jnn.2009.1790

23. K.J. Kim, V.P. Janule, Dynamic surface tension of aqueous lithium bromide with 2-ethyl-1-hexanol. Int. Commun. Heat Mass Transfer 21(6), 839-848 (1994). https://doi.org/10.1016/0735-1933(94) 90037-X

24. Z. Yuan, K. Herold, Surface tension of pure water and aqueous lithium bromide with 2-ethyl-hexanol. Appl. Therm. Eng. 21(8), 881-897 (2001). https://doi.org/10.1016/S1359-4311(00)00088-0

25. P. Kisari, K. Wang, O. Abdelaziz, E.A. Vineyard, Crystallization temperature of aqueous lithium bromide solutions at low evaporation temperature. United States: N. p., (2010). Web.

26. O'Grady, Crystallization and precipitation, guide to effective process development. (Mettler Toledo AutoChem, Inc., 2014) www. mt.com/Crystallization

27. C. Vereda, R. Ventas, A. Lecuona, R. Lopez, Single-effect absorption refrigeration cycle boosted with an ejector-adiabatic absorber using a single solution pump. Int. J. Refrig 38(1), 22-29 (2014). https://doi.org/10.1016/j.ijrefrig.2013.10.010
28. G. Chen, O. Volovyk, V. Ierin, K. Shestopalov, Int. J. Refrig. 81, 33-40 (2017)

29. G. Chen, V. Ierin, K. Shestopalov, O. Volovyk, Design-theoretical study of hybrid $\mathrm{CO}_{2}$ transcritical mechanical compression-ejector cooling cycle. Refrig. Sci. Technol. (2015). https://doi.org/10. 18462/iir.icr.2015.0321

30. G. Chen, V. Zhelezny, O. Khliyeva, K. Shestopalov, V. Ierin, Ecological and energy efficiency analysis of reasonability application of ejector air conditioner compared to vapour compression equipment. Refrig. Sci. Technol. (2015). https://doi.org/10.18462/iir.icr. 2015.0787

31. S. Manu, T.K. Chandrashekar, A simulation study on performance evaluation of single-stage $\mathrm{LiBr}-\mathrm{H} 2 \mathrm{O}$ vapour absorption heat pump for chip cooling. Int. J. Sustain. Built Environ. 5(2), 370-386 (2016). https://doi.org/10.1016/j.ijsbe.2016.08.002

32. C. Rubio-Maya, J.J. Pacheco-Ibarra, J.M. Belman-Flores, S.R. Galvan-Gonzalez, C. Mendoza-Covarrubias, Appl. Therm. Eng. 37, 10-18 (2012)

33 K. Ebrahimi, G.F. Jones, A.S. Fleischer, Thermo-economic analysis of steady state waste heat recovery in data centres using absorption refrigeration. Appl. Energ. 139, 384-397 (2015). https://doi.org/10.1016/j.apenergy.2014.10.067

34. K.A. Joudi, A.H. Lafta, Simulation of a simple absorption refrigeration system. Energy Convers. Manage. 42(13), 1575-1605 (2001). https://doi.org/10.1016/S0196-8904(00)00155-2

35 H.S. Majdi, Performance evaluation of combined ejector $\mathrm{LiBr} /$ H2O absorption cooling cycle. Case Stud. Therm. Eng. 7, 25-35 (2016). https://doi.org/10.1016/j.csite.2016.01.003

36. A. Arya, M.M. Sarafraz, S. Shahmiri, S.A.H. Madani, V. Nikkhah, S.M. Nakhjavani, Thermal performance analysis of a flat heat pipe working with carbon nanotube-water nanofluid for cooling of a high heat flux heater. Heat Mass Transfer 54, 985-997 (2018). https://doi.org/10.1007/s00231-017-2201-6

37. M.M. Sarafraz, F. Hormozi, Pool boiling heat transfer to dilute copper oxide aqueous nanofluids. Int. J. Therm. Sci. 90, 224-237 (2015). https://doi.org/10.1016/j.ijthermalsci.2014.12.014

38. S. Yousefzadeh, H. Rajabi, N. Ghajari, M.M. Sarafraz, O.A. Akbari, M. Goodarzi, Numerical investigation of mixed convection heat transfer behaviour of nanofluid in a cavity with different heat transfer areas. J. Therm. Anal. Calorim. 140, 2779-2803 (2020). https://doi.org/10.1007/s10973-019-09018-6

39. Z. Li, M.M. Sarafraz, A. Mazinani, H. Moria, I. Tlili, T.A. Alkanhal, M. Goodarzi, M.R. Safaei, Operation analysis, response and performance evaluation of a pulsating heat pipe for low temperature heat recovery. Energy Convers. Manage. 222, 113230 (2020). https://doi.org/10.1016/j.enconman.2020.113230

40. M.M. Sarafraz, F. Hormozi, Forced convective and nucleate flow boiling heat transfer to alumina nanofluids. Chem. Eng. 58(1), 37-46 (2014). https://doi.org/10.3311/PPch.2206

41. U.A. Muhammad, D. Bhattacharyya, J.L. Endrino, S. Preparation of binary nanofluid with heat transfer additives by particles surface functionalization, Emergent Materials, (2021). https://doi. org/10.1007/s42247-021-00260-Z

42. S.J. Kline, F.A. McClintock, Describing uncertainties in singlesample experiments. Mech. Eng. 75(1), 3-8 (1953) 